\title{
Prática e didática da música de câmara
}

\author{
Practice and didactics of chamber music
}

Sonia Ray

LPCM-EMAC-UFG

sonia_ray@ufg.br 


\section{Resumo}

Questões relativas à fundamentação da atuação do músico camerista e do professor de música de câmera são o foco deste texto. A pouca atenção de pesquisadores da área de performance musical aos fundamentos da realização e ensino desta prática tem levado a uma multiplicidade, por vezes desorientada, de ações na formação do camerista. O objetivo principal da discussão aqui apresentada é gerar reflexão sobre o tema, bem como oferecer diretrizes para estudantes e professores de música de câmara. Partindo dos conceitos de Performance Musical (2015a) e Pedagogia da Performance Musical (RAY, 2015b), são apresentados fundamentos e sugestões de organização didática da música de câmara em nível intermediário (graduação). Para tanto, o texto está organizado em três partes principais: 1) Fundamentos para uma Didática da Música de Câmara, 2) Elementos da prática e didática da música de câmara e 3) Considerações para o planejamento da disciplina. A discussão e sugestões aqui apresentadas evidenciam os benefícios de estudos conceituais focados na prática e didática da música de câmara, sobretudo em processos formais de ensino.

Palavras-chave: Pedagogia da Performance Musical, didática da música de câmera, formação do músico camerista.

\section{Abstract}

This text focuses on questions related to fundaments for the chamber musician and chamber music teacher's work. The little attention music performance scholars have been given to the fundaments of its practice and teaching, has caused many uninformed instructions throughout chamber musicians' education. The main goal of the present paper is to discuss the theme as well as to offer directions to both chamber music students and teachers. Based on the concepts Musical Performance (Ray, 2015a) and Musical Performance Pedagogy (Ray, 2015b), this article presents fundaments and suggestions on how to organize an undergraduate chamber musiccourse. The text is organized in three main parts: 1) Fundamental approaches to chamber music didactics; 2 Practice and didacts of chamber music elements; and 3) Considerations on how to plan a chamber music course. The discussions and suggestions here presented showed clearly that there are benefits of the conceptual studies addressed to chamber music students and teachers, particularly those involved in formal educational.

Keywords: Music Performance Pedagogy, Didacts of chamber music, Chamber musician's education.

\footnotetext{
1 Graduada em Composição e Regência pela Universidade Estadual Paulista em 1993. Concluiu seus cursos de Mestrado e Doutorado na Universidade de lowa. É sócia fundadora da Associação Brasileira de Contrabaixistas. Na Escola de Música da Universidade Federal de Goiás (UFG) é professora dos Cursos de Graduação e Pós-Graduação e tem projetos em andamento com temas variados relacionados à divulgação do contrabaixo e da música brasileira.
} 


\section{Introdução}

As discussões sobre música de câmara pouco têm se detido em questões conceituais, particularmente no que tange aos fundamentos pedagógicos nos quais esta prática pode se alicerçar. A questão é recorrente em disciplinas da parte prática da performance musical, que traz uma tradição de ação baseada em experiências próprias pouco compartilhadas e que se reproduzem verticalmente entre professores e alunos, advindas de duas premissas: 1) performers acreditam que os procedimentos que foram eficientes em sua formação serão bons para seus alunos; e 2) performers não acreditam que precisem de uma teoria para orientar sua prática docente. Assim, a crença de que a experiência do professor, uma vez bem-sucedida, seja suficiente para justificar sua prática pedagógica e definir uma conduta didática precisa, afasta artistas-docentes de estudos teóricos que podem auxiliar nesse processo.

Pensando particularmente na prática da música de câmara em cursos superiores de música, onde o aluno tem sua introdução formal a esta atividade e ao repertório disponível, este texto tem o objetivo principal de gerar reflexão sobre prática e didática da música de câmara, bem como oferecer diretrizes conceituais para estudantes e professores que nela atuam. Está organizado em três partes: a primeira traz uma visão teórica que se fundamenta em dois conceitos defendidos por Ray (2015a, 2015b e 2019); a segunda elenca elementos da prática e da didática da música de câmera, alicerçados por estudos específicos sobre preparação da performance musical; e a terceira aborda fundamentos para a organização e planejamento da disciplina.

\section{Fundamentos para uma Didática da Música de Câmara}

A importância de fundamentar uma atuação didática, apesar de sua evidente necessidade, é pouco discutida no ensino de música, com vistas à formação de instrumentistas, cantores e regentes. A prática do ensino é exercida com opções didáticas que, não raramente, partem de experiências individuais de artistas-professores experientes e confiantes nos êxitos de sua trajetória particular, como demonstrado no experimento desenvolvido recentemente com 50 professores experientes no ensino da performance musical (RAY, 2019, p.58-62).

O experimento fez parte da pesquisa que definiu um conceito para Pedagogia da Performance Musical (PPM) como

[...] um campo de conhecimento que emerge da relação dialética entre educação e conhecimentos musicais, fundamentado nas teorias e práticas formadoras do músico que necessariamente atua em público ou com a expectativa de estar em público em sua atividade principal. Não é campo independente, posto que o fazer musical é interdisciplinar por natureza, envolvendo aspectos múltiplos sempre orientados pela disciplina ${ }^{2}$ música. (RAY, 2019, p.27). 
Neste sentido, discutir fundamentos para uma didática da música de câmara implica localizar no referido conceito os alicerces para se definir a didática desejada.

Ao considerar a PPM uma área interdisciplinar, o conceito abriga a ideia de que não se faz performance musical apenas com o conhecimento de uma única área, no caso, a música. Como diz Cazarim (2007),

A formação do performer musical envolve, além dos aspectos teóricos e técnicos inerentes à sua prática musical, saberes de várias áreas do conhecimento, como a psicologia, aspectos músculo esqueléticos [sic], física (acústica), filosofia, entre outras. Por isso, a performance musical tem se caracterizado como um campo de estudos interdisciplinares. (CAZARIM, 2007, p.582).

Apesar de ocupar um lugar principal e indispensável, a música precisa ser integrada a outras áreas do conhecimento para que uma performance musical seja construída. Para tal, considera-se o conceito de Performance Musical (PM), desenvolvido em 2005, quando da apresentação dos Elementos da Performance Musical, aqui revisados. À época, a PM fora pensada como o "momento da performance", o que não considero mais pertinente, uma vez que se trata de uma atividade interdisciplinar e que extrapola a ação de um ou mais elementos para se tornar o contexto todo em que ocorre a exposição do músico (ou a expectativa de estar exposto) à apreciação de outro(s). Assim, atualizando minha afirmação de 2015, diria que a Performance Musical se dá na prática do músico que necessariamente atua em público ou com a expectativa de estar em público em sua atividade principal.

\footnotetext{
Podemos estar falando de um recital, um concerto solista (ou camerista), um concerto com grandes conjuntos (como coral ou orquestra), uma prova com banca (em escola, concurso ou audição para emprego) ou até mesmo uma aula (onde frequentemente se "simula" uma apresentação). O fato aparentemente simples de estar sendo observado muda a atitude do performer diante da música que ele executa. [Assim,] toda performance musical envolve pelo menos um agente (instrumentista, cantor ou regente) e quatro fundamentos: 1) o domínio da manipulação física do instrumento; 2) o amplo conhecimento do texto musical a ser interpretado, bem como as considerações estéticas a ele relacionadas; 3) condições de interagir com os aspectos psicológicos envolvidos no exercer da profissão e 4) condições de reconhecer os limites do seu corpo constantemente e prioritariamente no contato como o instrumento. (RAY, 2015a, p.39).
}

Na especificidade da didática da música de câmara, há ainda que se considerar na PM a mistura de fontes sonoras distintas (instrumentos ou vozes diferentes), conceitos variados de execução de estilos, níveis de execução técnica distintos (muito comum entre alunos de um mesmo período nas IES), multiculturalismo (especialmente num país com as dimensões do Brasil, onde as IES recebem alunos de várias partes do país) e experiência prévia em tocar com outros tipos de instrumento (experiência essa que é menos comum em instrumentistas de instrumentos harmônicos ou não orquestrais). No ensino da performance musical, os aspectos cognitivos assumem papel de grande importância, tanto para a formação do aluno quanto para a preparação do professor. Nas palavras de Villegas (2017), 
O nível pedagógico está relacionado à cognição da performance musical através de seus componentes afetivos, motores e cognitivos, uma vez que esses componentes se referem ao armazenamento de informações, sensações e ações de longo prazo (RUSINEK, 2003), portanto, o estudante teria a capacidade de reproduzir os conhecimentos adquiridos tanto em seu instrumento como na prática da música de câmara, convertendo-os em um suporte pedagógico para a formação musical integral e para o seu futuro trabalho docente ${ }^{3}$. (VILLEGAS, 2017, p.473). [Trad. da Autora]

Uma visão pedagógica que possa ser ampla o suficiente para acessar os componentes dos quais nos fala o autor e ainda estar próxima do fazer artístico-criativo indispensável na prática da música de câmara precisa considerar três agentes principais: a instituição, o professor e o aluno.

Uma Instituição de Ensino Superior (IES) se faz conhecer através de documentos obrigatórios que definem sua missão, objetivos, compromisso social, educacional e pedagógico. Este último, em universidades regulamentadas pelo Ministério da Educação (MEC), é definido em um Projeto Político Pedagógico (PPP). Nele se baseiam os Projetos Pedagógicos dos Cursos (PPC), sobre os quais se constroem os Planos de Ensino de cada disciplina num determinado curso. Não há novidades aqui para professores que lidam com disciplinas estruturais, musicológicas ou ligadas diretamente à área de educação, mas estas informações costumam estar bem distantes da prática dos professores de performance musical, naturalmente sem familiaridade com aspectos legislativos da sua prática. Contudo, se atentos a estes documentos, professores localizariam com certa facilidade o contexto em que sua disciplina prática se insere dentro da matriz curricular do curso, bem como as expectativas do mesmo para o perfil do aluno que se pretende formar.

Seguindo esta lógica, conhecer a visão pedagógica da IES tornaria possível a definição de uma visão pedagógica que una concepções do professor de um curso com as diretrizes da IES, no sentido de nortear as ações didáticas deste docente visando à formação do músico-camerista. Da mesma forma, seria possível reunir um grupo de professores de instrumento (da mesma família ou não) para unirem suas visões pedagógicas e implementarem ações didáticas comuns num determinado curso. Cabe ainda ressaltar que a didática que se deseja fundamentar é justamente "uma teoria da instrução e do ensino" (LIBÂNEO, 1990, p.53), um conceito que mantém intrinsicamente relacionados instrução, currículo, metodologias e técnicas (LIBÂNEO, 1990, p.53).

O caminho que se propõe para unir as concepções pedagógicas do professor, as diretrizes da IES e a realidade do aluno parte de dois conceitos preliminares aqui apresentados: Performance Musical (PM) e Pedagogia da Performance Musical (PPM). O professor, assim, disporá de elementos para se colocar dentro das seguintes premissas: 1) Se a PM se dá na prática do músico (instrumentista, cantor ou regente) que se expõe 
à crítica de outro, é necessário considerar como se prepara um grupo de câmara para esta exposição; 2) Se a PM se estabelece também em situações de expectativa de estar em público, o aluno precisa ser preparado para tais situações; 3) Se a PM prescinde do domínio da manipulação física do instrumento, preparar o aluno para este domínio atuando em grupo é demanda obrigatória da música de câmara; 4) Se a PPM assume que o fazer musical é interdisciplinar por natureza, é fundamental que aspectos interdisciplinares sejam abordados na preparação do músico-camerista; 5) Se a PPM emerge da relação dialética entre educação e conhecimentos musicais, tal relação precisa ser estabelecida na abordagem do professor com os grupos de câmara que orienta; e 6) Se a PPM envolve aspectos múltiplos sempre orientados pela disciplina música, é necessário localizar na docência e na prática da música de câmara como essa disciplina orienta aspectos didáticos.

Partindo dessas seis premissas, o professor poderá traçar seus caminhos didáticos, ou seja, instrução, currículo, metodologias e técnicas para o ensino da música de câmara. Poderá também buscar referências para embasar suas decisões através de materiais que sirvam ao seu propósito didático (publicações em texto, material audiovisual, partituras, encartes de gravações, notas de programas, dissertações e teses etc.) e aliá-los à sua experiência pessoal de ser (ou ter sido) um músico-camerista. Veremos estes caminhos em detalhes a seguir.

\section{Elementos da prática e da didática da música de câmara}

A prática da música de câmara é ensinada nos cursos superiores de música como parte indispensável da formação do instrumentista e do cantor. Pesquisas sobre a preparação para performance musical frequentemente abordam questões relacionadas à música de câmara, porém pouco discutem a preparação do professor desta modalidade da performance. No Brasil, textos em periódicos e Anais de congressos que discutem música de câmara são geralmente concentrados em discussões de cunho interpretativo, tangenciando aspectos musicológicos e/ou analíticos. Estes textos, quando abordam música de câmara, tendem a abordar grupos de instrumentos iguais ou da mesma família, a exemplo de XXX (2015) e Reis e De Biaggi (2018). Poucos autores, a exemplo de Cerqueira (2012), dedicam suas pesquisas a aspectos conceituais sobre o ensino da performance musical ou da música de câmara.

Diferentemente do Brasil, autores que fundamentam grande parte dos textos sobre performance musical e cognição no Ocidente abordam aspectos pedagógicos e a prática camerística com frequência, inclusive em diversas publicações em colaboração entre eles. Nos primeiros dez anos do século XXI, destacaram-se cinco publicações densas, cujos capítulos, escritos por especialistas, continuam gerando citações e embasando pesquisas mundo afora. São eles: Parncutt e McPherson (2002), Rink (2002), Williamon (2004), Gordon (2006), Hallam (2006) e Klickstein (2009). 
Contudo, vários desses autores, ao ressaltar as competências que um camerista deve adquirir para ser bem-sucedido, ou seja, ser capaz de realizar performances públicas com qualidade, abordam aspectos que interessam à Pedagogia da Performance Musical. Além da preocupação com a formação artística, está também a importância do fazer coletivo inerente à música de câmara, que contribui significativamente para a formação do indivíduo.

\begin{abstract}
Embora seja importante que estudantes de música se baseiem em suas experiências artísticas para tomar decisões interpretativas, assume-se que outros conhecimentos sejam essenciais para a formação musical. Portanto, faz-se necessário desenvolver didáticas que auxiliem estudantes de música de câmara a valorizar outros tipos de conhecimento musical, assim como a interação da teoria com a prática. (YAMAUCHI; SINICO; GUALDA, 2012, p.160).
\end{abstract}

Corroborando a conclusão dos autores, as sugestões a seguir oferecem ao mesmo tempo objetivos e metodologias que podem auxiliar o professor a embasar suas decisões por materiais (publicações em texto, material audiovisual, partituras, encartes de gravações, notas de programas, dissertações e teses etc.) que sirvam ao seu propósito didático, sempre aliados à sua experiência pessoal.

\title{
2.1 Objetivos e metodologias
}

Os elementos da prática e da didática da música de câmara a seguir sugerem simultaneamente objetivos e metodologias e seguem a ordem das seis premissas elencadas na parte 1 deste artigo, mas não há hierarquia envolvida na sequência.

\subsubsection{Exposição ao público}

A adoção de performances públicas curtas e programadas ao longo do semestre colocam em "teste" os estudos em andamento e preparam o grupo de câmara para as provas de banca e para um futuro de muitas exposições públicas. Sempre importante ir aumentando o tempo destas performances curtas, começando com peças curtas ou movimento de obras ( 3 a 5 minutos) até chegar a obras mais extensas ( 15 a 20 minutos) a cada semestre.

\subsubsection{Expectativa de estar exposto}

O ensino da expectativa de estar em público pode ser realizado através de simulados de prova entre alunos de uma turma ou com gravações. Ambas as metodologias promovem a sensação de estar sendo observado, gerando uma expectativa que pode ser até mais tensa que de fato estar em público, pois o aluno sabe que a gravação poderá ser ouvida por outros, e, sobretudo, por ele mesmo. 


\subsubsection{Domínio do instrumento}

Existem diferenças em dominar um instrumento em atuação solo ou em grupos de câmara que podem dificultar o processo de assimilação de conteúdo da aula de MC. A preparação deve envolver exercícios que levem cada membro a perceber como seu instrumento se insere na sonoridade do grupo. A técnica sofrerá ajustes para que haja um resultado sonoro que amalgame diferentes fontes sonoras. Um recurso bastante indicado, principalmente para o primeiro semestre da disciplina, é a escolha de repertório que permita experimentos timbrísticos (a exemplo de obras abertas onde instrumentos de famílias diferentes podem ser mesclados, e elementos como altura, divisão rítmica e dinâmica podem ser escolhidos pelo grupo - vide obras de John Cage e Philip Glass, entre outros). A escolha/busca de repertório inclui também a realização de arranjos, adaptações e transcrições pelo grupo, colocando em prática o conhecimento de outras competências dos músicos em função da MC. 2.1.4 Aspectos interdisciplinares

Aspectos cognitivos da aprendizagem musical estão entre os aspectos interdisciplinares mais recorrentes na preparação da PM. Os estudos sobre memória (ter sempre um pequeno desafio de tocar algo memorizado, ainda que curto); estudos de fisiologia (analisar a musculatura utilizada nos movimentos necessários para a execução de cada instrumento e para a comunicação efetiva do grupo); estudos de percepção auditiva, corporal, visual e tátil (que devem ser estimulados em exercícios de aquecimento no início das aulas e em momentos específicos da preparação da aula, de forma a localizar pontos de apoio que mantenham o grupo conectado e interagindo ao longo da performance). Além disso, os estudos de psicologia da performance musical, apesar de ainda tímidos na universidade brasileira (RAY; KAMINSKI, 2011, 2012, 2016), são fundamentais para que o grupo aprenda a estabelecer metas plausíveis de forma integrada.

\subsubsection{Educação e música}

A "relação dialética entre educação e música" na abordagem do professor indica que este deve ser o agente que orienta as etapas metodológicas, partindo dos objetivos musicais e mesclando procedimentos didáticos, tanto advindos da prática musical quanto do cânone tradicional da área de educação. A estruturação de aulas pode seguir roteiros definidos por estudos da didática, mas as aulas devem sofrer as alterações necessárias para que se adaptem às necessidades da aula de música de câmara. Da mesma forma, metodologias em sala de aula podem mesclar abordagens individuais e coletivas com aproveitamento de todos, desde que todos os alunos do grupo tenham uma função dentro da metodologia adotada (por exemplo: observadores de diferentes aspectos, executores da ação, auxiliares de execução, orientadores da ação, registradores da ação etc.) 


\subsubsection{Música como orientação principal}

A disciplina música, em seu papel orientador no ensino da prática camerística, determina os objetivos de cada etapa metodológica. O papel de todas as demais áreas que auxiliam a formação do músico camerista só pode ser justificado a partir do objetivo primeiro estabelecido pelo conhecimento musical que se quer adquirir. No caso, formar o músico camerista. Assim, é fundamental que se aprenda e ensine mesclando experiências artísticas pessoais e registros de estudos formais publicados.

Importante ressaltar que os aspectos da interação artística entre músicos e a interpretação são pontos de partida indispensáveis para determinar planos de estudo, repertório e os demais aspectos previstos nas premissas acima na formação individual e coletiva dos alunos em um grupo de câmara.

\section{Considerações sobre o planejamento da disciplina MC}

O planejamento da disciplina música de câmara no ensino superior de Música (chamado de Plano de Ensino - PE) guarda relação intrínseca com o Projeto Pedagógico do Curso (PPC) na qual essa se insere. Por isso, há que se considerar um perfil de curso para que se possa definir o PE. Importante considerar as referências sobre prática de música de câmara colocadas ao longo do presente texto, pois a intenção nesta parte é justamente destacar a necessidade de se refletir sobre essas referências e extrair delas conceitos a serem aplicados no PE. Aplicações não serão propostas aqui, pois esta deria uma discussão que extrapolaria a dimensão de um artigo. Além disso, não se pretende aqui apresentar um 'passo-a-passo' sobre elaboração de $\mathrm{PE}$, mas sim uma discussão sobre 'como se pensa ou se fundamenta' esta elaboração.

É preciso compreender a importância do PE dentro do contexto do ensino formal e adotar um formato de apresentação a ser seguido. Entende-se aqui que o PE é um instrumento que guia o professor no seu trabalho semanal, ajudando-o a manter-se dentro dos objetivos e conteúdos definidos. Já para o discente permite uma preparação antecipada dos assuntos a serem abordados diminuindo a expectativa deste com relação ao que será estudado no período, além de ajudá-lo a se preparar para as aulas.

A maior dificuldade do professor, contudo, é não ter sido formado sob métodos consolidados de ensino de performance musical em geral (RAY, 2015b) nem da performance da MC. A variedade de métodos empíricos aplicados na formação do camerista é o elemento que mais distancia o professor de definir um método a ser aplicado com seus alunos. Assim, o foco nesta parte é refletir sobre como mesclar o conhecimento tácito do camerista-professor com a adoção ou criação de métodos de ensino desta disciplina curricular.

As instituições de grande porte (como universidades) costumam ter um modelo definido pela coordenação pedagógica de seus cursos. Porém, a estrutura básica de um PE é encontrada em várias publicações sobre o tema (a exemplo de sites de pró-reitorias de graduação de IES), que quase sempre incluem um formulário-modelo. Libâneo 
(1990, p.51-76) discute os itens de um plano de ensino em sua publicação dedicada à didática, na qual corrobora a ideia de que alguns itens são indispensáveis para o PE de qualquer área do conhecimento. O que os PE têm em comum é a obrigatoriedade de alguns itens estruturais, como identificação, ementa e objetivo, metodologia e materiais, conteúdo, formas de avaliação e bibliografia. O detalhamento a seguir, apesar de comum a qualquer disciplina curricular, é pouco discutido na concepção didática do camerista-professor e precisa ser desmembrada para que este possa considerar como se inserir neste contexto teórico. Apesar de não ser um 'passo-a-passo' o texto apresenta algumas considerações aplicativas mesclando conceitos da disciplina do conhecimento educação, sustentadas pela disciplina do conhecimento música, como proposto pelo conceito de PPM (RAY, 2015b) 3.1 A identificação é um cabeçalho onde devem constar o nome da IES, do curso e da disciplina, além da carga horária semestral, dia, sala e horário dos encontros semanais, nome e identificação do professor. São informações básicas que identificam a disciplina no curso e na IES.

Para fazer isso o docente não precisa ter amplo conhecimento de tabelas e gráficos. Basta incluir as informações. Se houver um formulário próprio da IES fica mais simples. Do contrário, pode ser simples assim (Tabela 1):

IES: UNIVERSIDADE XXX

Curso: BACHARELADO EM MÚSICA

Disciplina: MÚSICA DE CÂMARA

Carga horária semestral: 64 horas/aula

Funcionamento (dia, sala e horário): quartas, sala 001, 10h10-12h00

Professor: XXX

Tabela 1: Identificação (cabeçalho) do PE

3.2 A ementa (do latim ementum), que também significa ideia ou pensamento, é expressa em um texto curto que serve como sustentação para conceitos e procedimentos de uma disciplina. Em geral composta por frases sem hierarquia, a ementa aponta pensamentos que permeiam o conteúdo que será abordado. Deve estar diretamente ligada ao perfil do aluno que o curso quer formar. A ementa deve constar no PC e não deve ser alterada pelo professor individualmente, pois é parte integrante de um documento que rege todo o curso. Desta forma, se houver mais professores para uma mesma disciplina, a ementa será o item que garantirá a coerência entre as atuações didáticas de cada um deles, evitando que se perca o "pensamento" estabelecido pelo curso no planejamento da disciplina em questão. O objetivo da disciplina, diferentemente da ementa, explicita onde se quer chegar com o conteúdo no período a que o PE se refere (semestre, ano, curso todo). Tende a ser mais detalhado quando semestral e mais genérico quando engloba vários semestres (ou o curso todo).

A construção de uma ementa de MC deve considerar a importância da disciplina no curso inteiro, isto é, como esta disciplina ajuda na construção do egresso que se quer formar. Se o curso tem por objetivo, por exemplo: formar um profissional capaci- 
tado para dominar o conhecimento musical, atuar como instrumentista/cantor e propagar o conhecimento adquirido em vias formais ou informais. Esta ementa pode partir da ideia de que, à disciplina MC compete cuidar o domínio do conhecimento associado a fazer música em conjunto. A ementa poderia ser: conhecimento e prática da música composta/adaptada ou arranjada para execução em grupos reduzidos de instrumentistas ou cantores em grupos homogêneos e/ou heterogêneos. O objetivo poderia ser: Instrumentalizar o músico para atuar como camerista lidando com estilos, gêneros e formações variadas ao longo de sua formação.

3.3 Metodologia, materiais e procedimentos são, na verdade, itens distintos que costumam ser incluídos em uma única etapa nos formulários, por vezes confundindo o professor. Metodologia se refere à forma de aplicação do método de ensinar. Materiais são os "instrumentos" através dos quais o ensino será efetuado (publicações, gravações... no caso da música, instrumentos musicais seriam considerados materiais indispensáveis). Procedimentos são etapas da metodologia, o passo a passo pretendido para se ensinar o conteúdo no decorrer dos encontros semanais.

As práticas metodológicas partem da visão pedagógica do professor (respeitando-se a IES). No caso de uma instituição pública de ensino superior, a visão certamente inclui, além da construção do conhecimento musical do aluno e sua capacidade de absorver e propagar o conhecimento adquirido para a comunidade. As escolhas metodológicas então, devem partir de uma visão mais holística possível, pois tais instituições em geral recebem alunos de realidades diferentes, com formações prévias distintas. Posto que estarão aprendendo a atuar em palco juntos, precisam de um método que abrigue a todos. Sugeriria a não adoção de um único método, mas sim a mesclagem de vários, dependendo do grupo a cada semestre, sempre embasados por uma visão pedagógica ampla.

O método mais tradicional e mais antigo de se ensinar performance musical é certamente a prática da repetição do mestre, o que se torna inviável em grupos de câmara heterogêneos ou que lidem com instrumentos/vozes não dominadas tecnicamente pelo professor. Nestes casos, seria mais coerente a adoção de estudos teórico-práticos de estilo/gênero do repertório escolhido. O método pode ser aplicado coletivamente antes e depois do início do estudo da/s obra/s e implica em observação e discussão de material audiovisual de obras de referência do compositor estudado e/ou de seus contemporâneos. Pode-se ainda adotar a prática de uma mesma articulação ou expressão existente no repertório em instrumentos distintos buscando diferenças e similaridades que atuarão cognitivamente de várias formas ao longo do estudo e performance do grupo.

Menos comuns, mas pertinente, é a utilização de métodos de musicalização que podem ser aplicados parcialmente no ensino da música de camerista, pois frequentemente propõem treino de percepção corporal (como Dalcroze) e auditiva (como Gainza e Fonterrada) que ampliam a capacidade de execução em conjunto do músico em processo de profissionalização. 
A escolha de materiais deve ser prevista no PE para grupos de instrumentos/vozes distintos. Um bom acervo físico ou eletrônico deve ser listado no plano como referência. Aqui professores e alunos precisam se abrir para possiblidades for a de sua zona de conforto e tentar explorar estilos e gêneros diferentes do que tenham sido estudados até o momento em suas vidas, mantendo sempre ávido o desejo de ampliar o conhecimento sobre MC. A associação com alunos de composição da IES também são fontes recomendadas de repertório. Estudos técnicos de instrumentos devem ser remetidos ao professor específico, pois o camerista não tem que dominar a técnica de todos os instrumentos/vozes que orienta. 3.4 Conteúdo (ou conteúdo programático) diz respeito ao que deve ser assimilado pelos alunos no período ao qual o PE se refere. No caso da MC, é comum que este seja detalhado e inclua também um "programa" com indicação de repertório e estudos musicais específicos dentro do assunto (ou assuntos) a ser ensinado.

O professor pode optar por definir repertório com o grupo, de acordo com o nível técnico de cada membro e do interesse de todos os envolvidos por um gênero/estilo específico, desde que dentro dos objetivos previstos para a disciplina. Qualquer repertório pode ser objeto do treino para exposição pública, porém, é necessário observar qual tipo de prática o grupo necessita para que o tocar em conjunto seja otimizado. Pode-se, inclusive, adotar obras que demandem níveis técnicos distintos entre os membros do grupo, proporcionando a todos uma experiência enriquecedora. Há muitas possibilidades a serem exploradas, por exemplo, ao trabalhar o conteúdo "sincronismo e articulação em súbitas mudanças de dinâmica' o programa pode ser composto por uma obra do período Clássico ou do Século XXI, que tendem a explorar estes recursos.

3.5 Formas de avaliação são obrigatórias, pois o professor deve descrever os critérios que usará para avaliar seus alunos. Parte desses critérios são definidos pela coordenação de curso (em provas de banca, por exemplo), porém, sempre há pelo menos uma parcial da nota que é dada individualmente pelo professor. Critérios de quaisquer avaliações a serem aplicadas na produção do aluno devem constar no PE.

De qualquer forma, o professor deve deixar claro no PE que critérios usará para sua avaliação individual. Na MC o conteúdo não pode ser avaliado se não houver estudo do grupo em momentos extraclasse. Assim, a avaliação de como o grupo se prepara para cada aula deve ser considerada, bem como a ausência de algum dos membros em aulas, o que, diferentemente de outras disciplinas curriculares, impede o desenvolvimento da prática dos demais.

3.6 A bibliografia reúne fontes que subsidiam as ações do professor ao planejar e ministrar a disciplina. Costuma ser confundida com materiais a serem utilizados em aulas, podendo até coincidir com alguns desses materiais, mas não é limitada a isso. Deve conter fontes de referência para o domínio da disciplina em questão. No caso da música de câmara, é fundamental que a bibliografia sirva de fundamento para o ensino da disciplina, independentemente dos instrumentos que venham a compor o grupo a ser orientado pelo professor. A prática camerística deve ser o foco. Fontes que abordam o estudo da performance musical podem ser adaptados e aplicados à prática camerística, 
além das referências específicas de preparação para a MC como alguns já citados no presente texto. Pode-se também adotar referências que inspirem o professor em sua atitude pedagógica, como visões filosóficas e abordagens sócio-culturais, desde que as fontes estejam disponíveis na biblioteca da IES ou on-line em sites seguros (SciELO, RILM, Web of Science etc.)

Cabe ressaltar que um plano existe para registrar uma intenção e servir como uma guia, e não como uma limitação ao trabalho do professor. Uma vez organizada e planejada a disciplina, eventuais alterações que se façam necessárias ao longo do semestre ou ao longo do curso ficam mais fáceis de serem realizadas e justificadas.

\section{Considerações finais}

Ao abordar a atuação do músico camerista e do professor de música de câmara, este texto discutiu fundamentos para ações na formação deste músico. As reflexões sobre o tema evidenciaram que os estudos sobre Pedagogia da Performance Musical no Brasil apenas tangenciam o ensino da música de câmara e ainda assim se limitam a abordagens que versam sobre aspectos analíticos e musicológicos envolvendo grupos de instrumentos iguais ou da mesma família.

Quanto aos fundamentos para uma Didática da Música de Câmara, partiu-se dos conceitos de Performance Musical (RAY, 2015a) e Pedagogia da Performance Musical (RAY, 2015b), constatou-se que uma visão pedagógica ampla o suficiente abarca as competências necessárias à formação, e um músico-camerista precisa integrar três agentes principais: a instituição, o professor e o aluno. Essa integração parte de seis premissas: 1) a prática da música de câmara precisa considerar a exposição ao público como um de seus objetivos; 2) a prática da música de câmara deve considerar também situações de expectativa de estar em público; 3 ) é obrigatório o treino do domínio do instrumento atuando em grupo; 4) é fundamental que aspectos interdisciplinares sejam abordados na preparação do músico-camerista; 5) a relação dialética entre educação e conhecimentos musicais deve estar presente; e 6) a prática da música de câmara deve ter a música como orientadora dos aspectos didáticos.

Quanto aos elementos da prática e da didática da música de câmera, são indicados objetivos e metodologias sobre as seis premissas apresentadas, que podem auxiliar o professor a embasar suas decisões por materiais didáticos a serem aplicados de forma sempre aliados à sua experiência pessoal.

Quanto à organização em planejamentos da disciplina música de câmara, foram apresentadas as bases para elaboração de Planos de Ensino considerando as visões propostas pela IES e pelo curso no qual a disciplina se insere. Concluiu-se que os estudos atuais sobre elaboração de PE têm em comum a obrigatoriedade de itens estruturais, como identificação; ementa e objetivo; metodologia e materiais, conteúdo, formas de avaliação e bibliografia, os quais são detalhados no texto. 
Fica evidente a grande contribuição que discussões conceituais têm sobre a prática da música de câmara e as ações didáticas aplicadas a seu ensino. A fundamentação da prática aqui discutida mostra o quanto estudos teóricos e a prática do músico-professor camerista poderiam ser mescladas trazendo mais uniformidade na formação deste músico. Documentos, como o plano de ensino, se visto como um suporte para a didática, pode otimizar as ações do professor e o aprendizado do aluno, pois sua elaboração em si exige reflexão sobre as razões que levam o professor a adotar procedimentos metodológicos e materiais em seu trabalho semanal na universidade.

Por fim, acredita-se que a reflexão e as sugestões apresentadas podem contribuir para o desenvolvimento dos estudos conceituais sobre prática e didática da música de câmara.

\section{Referências}

CAZARIM, T. A percepção do corpo na performance musical: o lugar da imagem corporal na prática camerística. In: SIMPÓSIO INTERNACIONAL DE COGNIÇÃO E ARTES MUSICAIS, 3., 2007, Salvador. Anais [...]. Salvador: UFBA, 2007. p. 582-587.

CERQUEIRA, D. L.; ZORZAL, R. C.; AVILA, G. A. de. Considerações sobre a aprendizagem da performance musical. Permusi, n. 26, p. 94-109, 2012. Disponível em: http://www.scielo.br/scielo.php?pid=S1517-75992012000200010\&script=sci_ abstract\&tlng=pt. Acesso em: 28 ago. 2019.

GORDON, S. Mastering art of performance: a primer for musicians. New York: Oxford University, 2006.

HALLAM, S. A practical guide to better teaching and learning. Oxford: Heinemann Educational, 2006. Cap. 8, p. 118-141.

KAMINSKI L.; RAY, S. In: SIMPÓSIO INTERNACIONAL DE COGNIÇÃO E ARTES MUSICAIS, 11., 2015, Pirenópolis. Anais [...]. Pirenópolis: UFG, 2015.

KLICKSTEIN, G. The musician's way: a guide to practice, performance, and wellness. New York: Oxford university, 2009.

LIBÂNEO, J. C. Didática. São Paulo: Cortez, 1990.

PARNCUTT, R.; McPHERSON, G. E. The science \& psychology of music performance. New York: Oxford University, 2002.

RAY, S. et al. Estudo exploratório sobre o impacto da informação sobre psicologia da performance no nível de estresse e ansiedade de músicos práticos brasileiros. Opus, v. 22, n. 2, p. 303-323, dez. 2016. 
RAY, S. KAMINSKI, L. C. O Atual estado da questão da disciplina psicologia na formação de músicos-intérpretes na academia brasileira. In: SIMPÓSIO INTERNACIONAL DE COGNIÇÃO A ARTES MUSICAIS, 8., Brasília, 2011, Anais..., Brasília, 2011.

RAY, S. KAMINSKI, L. C.. Psicologia da performance na formação acadêmica do performer In: CONGRESSO DA ASSOCIAÇÃO NACIONAL DE PESQUISA E PÓSGRADUAÇÃO EM MÚSICA, 22., João Pessoa, 2012, Anais..., João Pessoa, 2012.

RAY, S. Performance Musical e suas Interfaces. Goiânia: Vieira, Irokun, 2015a.

RAY, S. Pedagogia da Performance Musical. Tese (Pós-Doutorado) - UFG, Goiânia, 2015b.

REIS, A.; DE BIAGGI, E. A homogeneidade sonora no quarteto de cordas: diferentes enfoques possíveis. In: CONGRESSO DA ASSOCIAÇÃO NACIONAL DE PESQUISA E PÓS-GRADUAÇÃO EM MÚSICA, 28., 2018, Manaus. Anais [...]. Manaus: UFAM, 2018. p. 1-8.

RINK, John (Ed.). Musical Performance: a guide to understanding. New York: Cambridge, 2002.

VILLEGAS, R. G. Música de cámara y aprendizaje significativo: una estrategia pedagógica para el fortalecimiento de los procesos académicos y musicales. In: SIMPÓSIO INTERNACIONAL DE COGNIÇÃO E ARTES MUSICAIS, 13., 2017, Curitiba. Anais [...]. Curitiba: UFPR, 2017. p. 468-476.

WILLIAMON, A. Musical Excellence: strategies and techniques to enhance performances. New York: Oxford University, 2004.

YAMAUCHI, R; SINICO, A.; GUALDA, F. O interesse pela reflexão teórica no processo de criação da interpretação: um estudo da prática interpretativa coletiva em música de câmara. In: SIMPÓSIO INTERNACIONAL DE COGNIÇÃO E ARTES MUSICAIS, 8., 2012, São Paulo. Anais [...]. São Paulo: UDESC, 2012. p. 156-161. 